\title{
TUMOR ESTROMAL GASTROINTESTINAL DE INTESTINO DELGADO
}

\author{
GASTROINTESTINAL STROMAL TUMOR OF SMALL BOWEL
}

\author{
Francisco Marivaldo Benício da Silva ${ }^{1}$ \\ Jefferson Soares Lemos, ACBC-PI ${ }^{2}$ \\ Marcos Gonçalves Nunes de Moraes ${ }^{2}$
}

\section{INTRODUÇÃO}

Os tumores estromais do trato gastrointestinal (tegis) representam lesões relativamente raras que crescem de elementos do tecido conjuntivo ao longo de toda extensão do trato gastrointestinal. ${ }^{1}$

Estes blastomas foram inicialmente identificados por estudos imuno-histoquímicos, evidenciando-se sua origem a partir de células mesenquimais indiferenciadas. ${ }^{2}$

Uma minoria destes neoplasmas, principalmente aqueles confinados ao esôfago e reto, revelou-se neoplasias bem diferenciadas, como leiomioma ou leiomiossarcoma. $^{1,2}$

A maioria dos TEGIs corresponde a um grupo heterogêneo de lesões que tem como denominador comum uma proliferação imatura de células epitelióides ou espiculadas que crescem das camadas muscular própria, muscular da mucosa ou entre elas, apresentado aspectos de diferenciação mióide, neural, gangliônica ou mista. ${ }^{1}$

$\mathrm{O}$ presente relato de caso pretende apresentar um tumor estromal de intestino delgado, com dois anos de evolução, em paciente do sexo masculino, com 46 anos de idade.

\section{RELATO DO CASO}

Paciente de 46 anos, sexo masculino, deu entrada neste serviço em 05/03/99, queixando-se de tumoração abdominal há dois anos, evoluindo nos últimos sete meses com melena, febre, vômitos pós-alimentares e emagrecimento.

Ao exame físico: mucosas hipocrômicas $(+++/ 4+)$, anictérico, caquético, ausculta cardiopulmonar normal; abdome globoso, flácido, doloroso à palpação superficial e profunda, com massa palpável, endurecida, móvel, ocupando todo o mesogástrio.

Exames complementares: (1) hemograma: hematócrito de $24 \%$ e hemoglobina de $7,3 \mathrm{~g} \%$; (2) trânsito de intestino delgado: massa calcificada em região mesogás- trica à esquerda, associada a trajetos fistulosos subjacentes (Figura 1); (3) tomografia computadorizada de abdome: volumosa lesão sólida, apresentando contornos lobulados, com área central hipodensa e discretas calcificações puntiformes no seu interior, em projeção de mesogástrio; (4) Rx de tórax: normal; (5) endoscopia digestiva alta: erosões planas limpas justapilóricas, ectasia vascular única bulbar e palidez difusa da mucosa. $\mathrm{O}$ paciente foi submetido à laparotomia com diagnóstico de tumor de intestino delgado. Foi ressecada massa tumoral medindo $16 \mathrm{~cm}$ em seu maior diâmetro (Figura 2), com um segmento de intestino delgado. Não havia comprometimento do peritônio, fígado ou linfonodos regionais.

O estudo anatomopatológico revelou massa com superfície externa ondulada e pardo-acinzentada com área de tecido adiposo e presença de intestino com serosa discretamente congesta. A superfície de corte mostrou-se lobulada e branco-acinzentada, com extensa zona necrótica central e áreas de hemorragia e de calcificação, contendo também mucosa intestinal pregueada, íntegra e branco-acinzentada.

No estudo imuno-histoquímico, os cortes histológicos foram incubados com um painel de anticorpos monoclonais e/ou policlonais, sendo os mesmos negativos para citoceratinas, desmina, actina muscular, colágeno tipo IV, proteína S-100 e cromogranina a. Os achados morfológicos foram superponíveis ao tumor estromal gastrointestinal.

\section{DISCUSSÃO}

O termo tumor estromal tem sido aplicado a neoplasias de células mesenquimais indiferenciadas. Recentes estudos imuno-histoquímicos e ultra-estruturais destas lesões mostraram que elas podem ser divididas em: 1) leiomiomas, que são positivos para marcadores de músculo liso e negativos para CD34 e proteína S100; 2) schwanomas, que são positivos para proteína S100 e negativos para

1. Residente de Cirurgia Geral do HSM.

2. Cirurgião do Serviço de Cirurgia Geral do HSM.

Recebido em 8/2/2000

Aceito para publicação em 17/8/2000

Trabalho Realizado no Hospital Santa Maria - HSM - Teresina-PI. 


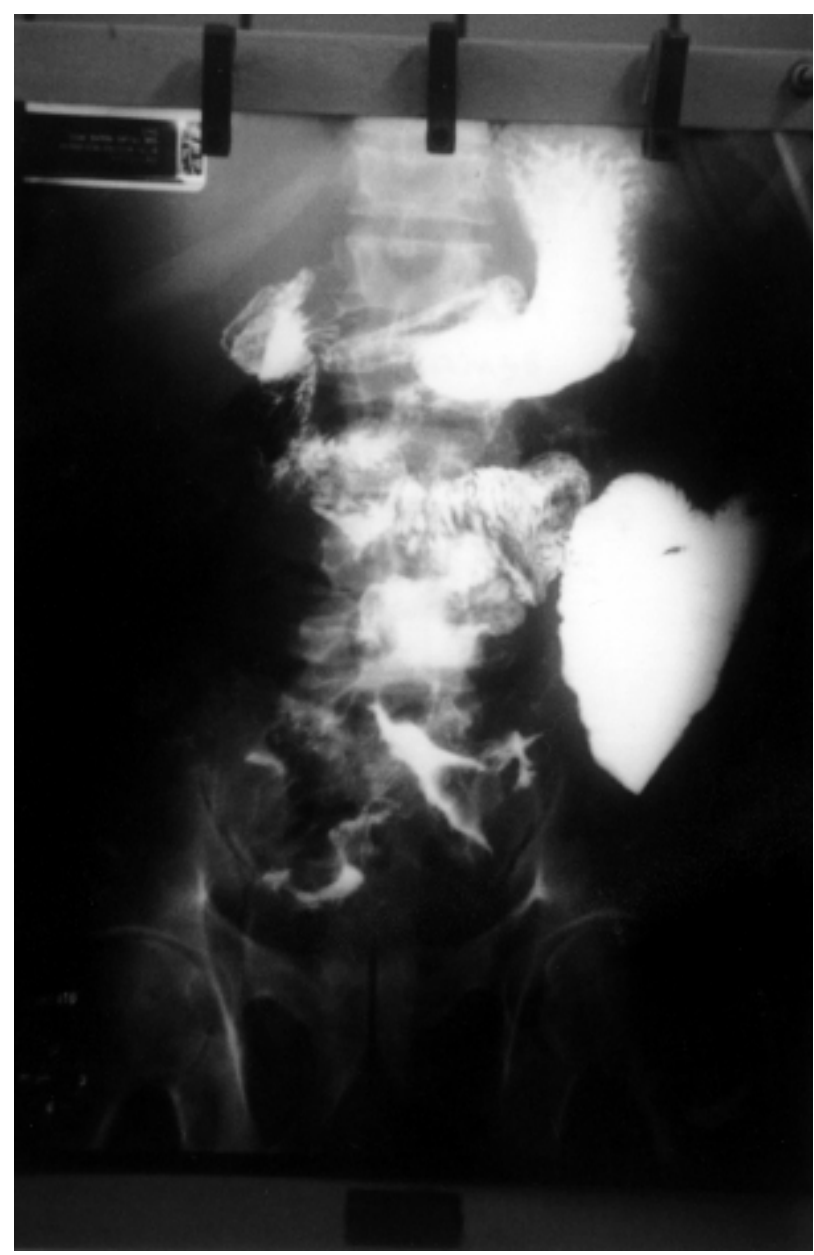

Figura 1 - Trânsito de intestino delgado, mostrando massa calcificada em região mesogástrica à esquerda, associada a trajetos fistulosos subjacentes.

marcadores de músculo liso e CD34; e 3) tumores estromais, que não possuem diferenciação a nenhum dos tipos celulares anteriores e a maioria é positiva para CD34. ${ }^{2,4}$

A definição de malignidade é um fator prognóstico importante. Estes neoplasmas foram classificados em categorias de malignidade histológica baseado no número de mitoses e no tamanho do tumor, como segue: 1) benigno <2; 2) indeterminado 2-5; e 3) maligno > 5 mitoses por 10 high power fields (HPF). Outra classificação leva em conta também o tamanho do tumor: 1) benigno, número de mitoses $<5$ por $50 \mathrm{HPF}$ e tamanho do tumor $<5 \mathrm{~cm} ; 2$ )

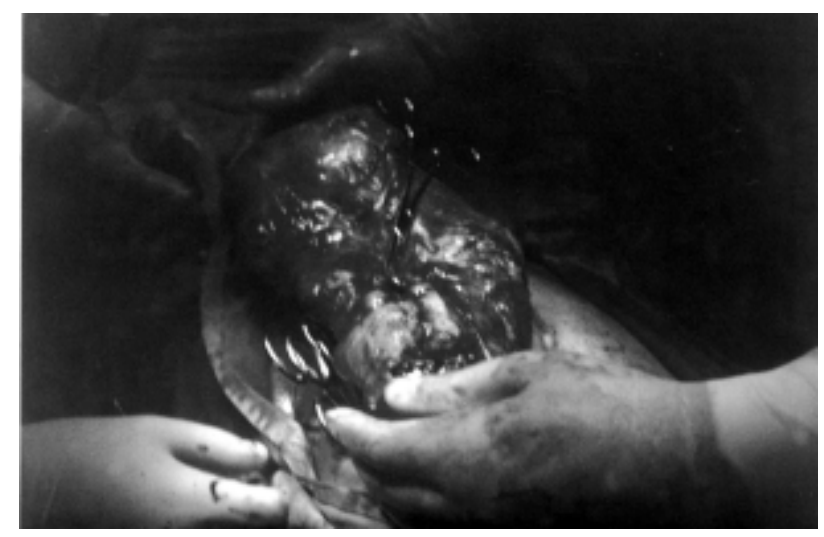

Figura 2 - Massa tumoral ressecada, medindo $16 \mathrm{~cm} \mathrm{em} \mathrm{seu}$ maior diâmetro.

indeterminado, mesmo número de mitoses e tamanho > $5 \mathrm{~cm}$; e 3) maligno, número de mitoses $>5$ por $50 \mathrm{HPF}$, qualquer que seja o tamanho da neoplasia. ${ }^{4}$ Os melhores critérios para definir fatores prognósticos úteis têm sido o tamanho do blastoma, invasão para tecidos e órgãos adjacentes, necrose e hemorragia, número de mitoses, celularidade, pleomorfismo nuclear e ploidia do DNA. ${ }^{5}$

O tratamento é cirúrgico. Os resultados dependem do tempo de evolução e extensão da doença. A sobrevida média é de 19 meses em pacientes com metástases e 12 meses naqueles com recorrência local ou em que não houve uma ressecção completa da neoplasia. A excisão total de uma lesão primária sem metástases é possível em $86 \%$ dos pacientes, os quais têm uma taxa de sobrevida de $54 \%$ em cinco anos. A recidiva da doença é mais comum no local de origem do tumor, peritônio e fígado. ${ }^{3}$

O diagnóstico anatomopatológico e imuno-histoquímico do caso foi compatível com tumor estromal gastrointestinal, com áreas de calcificação distrófica e com perfuração intestinal intraneoplásica. Apesar de discreta atipia celular, a lesão, dado o seu tamanho e a presença de áreas de necrose e de hemorragia em sua superfície foi considerada maligna e as margens de ressecção cirúrgica foram negativas para malignidade.

Não foi possível acrescentar dados em relação ao seguimento do paciente, tendo em vista que o mesmo não compareceu para a reavaliação na data prevista e não se conseguiu entrar em contato. Apesar de raro, o tegi deve ser considerado no diagnóstico diferencial de tumoração abdominal com melena, vômitos e emagrecimento.

\footnotetext{
ABSTRACT

Stromal tumors of the gastrointestinal tract (gists) represent relatively rare lesions that arise from connective tissue elements located along the entire length of the gut. They were initially identified by immunohistochemical investigation, proving their origin from nondifferentiated mesenchymal cells. Only a minority of this lesions, mainly those confined to the esophagus and rectum, have been shown to correspond to mature, well-differentiated types of neoplasms such as leiomyoma or leiomyosarcoma. The majority of gists corresponds to a heterogeneous group of lesions that have as their common denominator an immature proliferation of epithelioid or spindle cells
} 
arising from its muscle layers, or between them, showing partial or incomplete myoide, neural, ganglionic, or mixed features of differentiation. This case report intends to show a gist of small bowel in a male, 46 years old, with a two-year of evolution.

Keywords: Gastrointestinal stromal tumor; CD34; Mesenchymal cells.

\section{REFERÊNCIAS}

1. Suster S, Arkadi M. Gastrointestinal stromal tumors. Semin Diagn Pathol 1996; 13(4):297-313.

2. Laky D, Halalau F. Gastrointestinal stromal tumors - a recently defined entity. Literature data and personal case report. Rom J Morphol Embryol 1995; 41(1-2):73-83.

3. DeMatteo RP. Two hundred gastrointestinal stromal tumors - recurrence patterns and prognostic factor for survival. - Ann Surg 2000; 231(1): 51-8.

4. Takahashi T, Kuwao S, Yanagihara M et al. A primary solitary tumor of the lesser omentum with immunohistochemical features of gastrointestinal stromal tumors. Am J Gastroenterol 1998; 93(11): 2269-2273.
5. Weidner N. The Difficult diagnosis in surgical pathology. Philadelphia: W.B. Sauders, 1996.

Endereço para correspondência:

Dr. Francisco Marivaldo B. Silva

Conj. João Emílio Falcão - Cristo Rei

Quadra 03 Bloco 11 apto. 201

64014-600 - Teresina-PI

E-mail: john@ranet.com.br 